\title{
Measuring Digital Development with Online Data Digital Economies in Eastern Europe and Central Asia
}

\author{
(Working Paper - 26/06/2020) \\ Fabian Braesemann ${ }^{12}$, Fabian Stephany ${ }^{2}$ \\ 1 Saïd Business School, University of Oxford, UK \\ 2 Oxford Internet Institute, University of Oxford, UK
}

\section{Introduction}

The Internet, like railways and roads in the past, is paving innovation and alters the way in which citizens, consumers, businesses, and governments function and interact with each other. This digital revolution is empowering societies. It opens new, effective, and scalable services for governments and the private sector. It provides us with a more adaptive, data-driven approach to decision making in many aspects of our life. The digitalisation is particularly relevant for developing countries, as they can seize the opportunity for leapfrogging in order to become part of the global digitalised economy. In times of the Covid-19 crisis, understanding the digital economy is more relevant than ever, as the pandemic forces whole societies to use digital tools to organise work at a distance, with important consequences for the economy [1].

\section{Figure1 1 here}

With the example of Eastern Europe and Central Asia 3 this work illustrates how openly available online data can be used to identify, monitor, and visualise trends in digital economic development. An interactive online dashboard (https://bit.ly/ eeca_dashboard) allows researchers, policy-makers, and the public to explore four aspects of digital development: E-services, online labour markets, online knowledge creation and access to online knowledge. The analyses of all four domains is explained in greater detail in the following sections. 18 Eastern European and Central Asian countries are ranked within each domain, and consequently summarised in an overall index on digital development, as illustrated in Figure 1 .

\section{E-Services}

Electronic services help governments and citizens to exchange information and improve the quality of governmental services in general [2]. E-services are measured by their acceptance, security, and functionality. All Eastern Europe and Central Asia countries are using online portals to expand their e-services. The quality of national governance

\footnotetext{
${ }^{3}$ This work is the result of a collaboration with the UNDP Eurasia Hub Istanbul.
} 
portals is measured by the Online Service Index $x^{4}$. On a scale from 0 to 1 , it measures a government's capability and willingness to provide services and communicate with its citizens electronically. While Russia (0.92), Turkey (0.89), and Kazakhstan (0.87) managed to gain momentum from 2003 to 2018, other countries, like Tajikistan (0.34) and Turkmenistan (0.13), remained on a low level over the last 15 years.

\section{Figure 2 here}

The Portal Response Index, on the other hand, shows us how citizens react to the services offered. The indicator is based on the number of visits on the national e-governance portal by 100,000 internet users. The e-governance portals of Russia and Turkey are frequently visited sites. Similarly, the e-service portals of Kazakhstan, Azerbaijan, Serbia, and Albania are popular web-pages, too. The e-governance portals of Georgia, Uzbekistan, and Mongolia do not manage to attract users.

Since security and trust are vital for the establishment of e-services, the National Cyber Security Index ${ }^{5}$ (NCSI) measures the security of national digital infrastructure. Only if citizens trust that their data is securely processed, will they start engaging with their government online. In 2018, France scored highest on the NCSI ranking with 83 out of 100 points. In Eastern Europe and Central Asia, Serbia (66), Georgia (65), Russia, and Ukraine (both 64) are the top performing countries.

\section{Online Labour Markets}

Digital technologies transform labour markets. Digital gig work, mediated by online platforms, increasingly supplements regular employment. The Online Labour Index, created by the Oxford Internet Institute, is the first economic indicator that provides an online gig economy equivalent to conventional labour market statistics [3]. It measures supply and demand of online freelance labour, which allows to grasp the importance of the gig economy across countries and occupations.

Overall, projects in 'software development and technology' build the largest share of online labour demand. Approximately, one third of all projects posted online fall in this category. The second most important category is 'creative and multimedia' with roughly a fifth to a quarter of all jobs listed on online labour platforms. The size of the online labour markets varies significantly between countries in the region. The supply in the larger countries Ukraine, Russia, Turkey and Serbia remained relatively constant in the studied period, while the supply from countries in Central Asia and the Caucasus was more volatile.

\subsection{Case Study for the Belgrade Digital Summit}

Complementing the cross-regional comparison of the four aspects of digital development in all countries of the region, this work provides a deep-dive into the online labour markets of the Western Balkans countries. The findings of this case study can be explored via an interactive online dashboard 6

4 https://www.ifo.de/DocDL/dicereport 412-db2.pdf

5 https://ncsi.ega.ee/methodology/

6 https://bit.ly/wb_dashboard 
Figure 3 here

Serbia and North Macedonia are the most active suppliers of online labour (see Figure 3). Most freelancers in the region work for buyers from North America and Europe. There is almost no network flow into the other direction. In other words, freelancers in the Western Balkans work for employers in high-income countries, in particular in North America. For them, online labour markets provide an additional source of income. The countries in the Western Balkans use their high-level of human capital and technical dexterity to gain high-skill employment by companies from high-income countries, without the need to migrate to these places.

Online labour participation in the region is clustered mostly in large urban areas and, overall, there is a vast excess supply of labour: $89 \%$ of the registered freelancers from the region did not get at least one project. Thus, for many online labour platforms are still not a viable option to on-site employment. One reason for the low participation (a phenomenon that is not limited to the Western Balkans countries) is that global demand for online labour is lower than supply. Firms in high-income countries need to build the organisational capacities to incorporate work from freelancers. In that respect, the organisational changes induced by the recent stay-at-home policies might actually be a chance for freelancers from developing countries, as firms now start to learn how to organise work at a distance [4]. Another important factor is that participation in global online labour markets requires a good level of English language skills.

For the success of online labour platforms as a means of economic development, it will be paramount to activate the large pool of potential freelancers in countries from the region. It will therefore be necessary to better match online labour supply to the needs of customers. For example, regionally focused platforms could be based on a language other than English and they might aim to connect domestic demand for knowledge work with people living in rural areas, who could particularly benefit from such employment opportunities [5].

\section{Online Knowledge Creation}

Computer code is a unique building block of the digital economy. It is openly shared and re-applied by developers worldwide. The online repository GitHul $\left.\right|^{7}$ allows users to store and share elements of code and programming knowledge. On Stack Overflow ${ }^{8}$ developers can address questions to their global peers [6]. Both platforms - together the largest online hubs for programmers - are developed in a network structure where users can follow each other.

Figure 4 here

Analyzing the connections between users in GitHub (Figure 4), we see that more users in the region follow people from other parts of the world than vice versa. That is, users from the region use the platforms to access digital programming know-how, but

7 http://www.github.com

8 http://www.stackoverflow.com 
they are less able to "export" their innovative programming solutions to other places. For example, $10 \%$ of all follow-relations that involve at least one user from the region, represent Russian users who follow programmers from North America. In contrast, only $3 \%$ of the network flows go into the other direction. Thus, one three Russian users who follows American users, there is only one Russian user who is followed by users from North America. Moreover, there is a low level of collaboration between users from countries within the region.

The digital economy in Eastern Europe and Central Asia could benefit from more interactions with users from other countries, who are deeply embedded in global flows of programming know-how [7]. For instance, lighthouse projects developed by users from countries of the region could bring international attention to the local coder communities (think of the Skype software, which was developed in Estonia and brought the Estonian tech-community into the spotlight).

\section{Online Knowledge Access}

Wikipedia is by far the largest online encyclopedia: the English Wikipedia version alone counts roughly 3,000 views per second. While usage data is only available on a very aggregated level, information about the edits to Wikipedia can be collected in much more detail. The contribution to Wikipedia content can be considered as a strong indicator of domain-specific knowledge and the ability to participate in the digital knowledge economy. For example, the share of English Wikipedia edits reflect the degree to which contributors participate in the global knowledge economy of Wikipedia [8]. In the region, we observe that particularly Central Asian countries are making more and more use of the platform. Here, Wikipedia views increased fourfold between 2015 and 2018. In Turkey and the Balkan countries, where Wikipedia is more commonly used, viewing rates remained on a stable level in the last three years. Overall, we observe that language barriers still affect the access to knowledge from global platforms like Wikipedia. As Figure 5 shows, many countries in Central Asia consult the Russian Wikipedia Version much more frequently than the English Wikipedia. However, the English language version of Wikipedia provides many more articles and in-depth information. In order to benefit from the digitalisation, it will be important for developing countries to enable all users access to global knowledge.

Figure 5 here

\section{Summary}

With the example of Eastern Europe and Central Asia, this work illustrates how online platform data can be used to identify, monitor, and visualise trends in digital economic development. Overall, we conclude that data from online platforms of the digital knowledge economy can provide a valuable complement to more traditional statistics to measure digital innovation and development. If the high dimensionality of the datasets being made available by global platforms is properly explored, they can provide a rich source of empirical information, which is urgently needed to identify bottlenecks and 
to design evidence-based digital development policies. The digital economy is a chance for developing countries, but they need to gain access to digital knowledge flows and employment opportunities. This requires more than just providing a broadband infrastructure. The key is skill development, focusing English language capacities and developing those digital skills that make people from countries of the region globally competitive. 



\subsection{Figures}

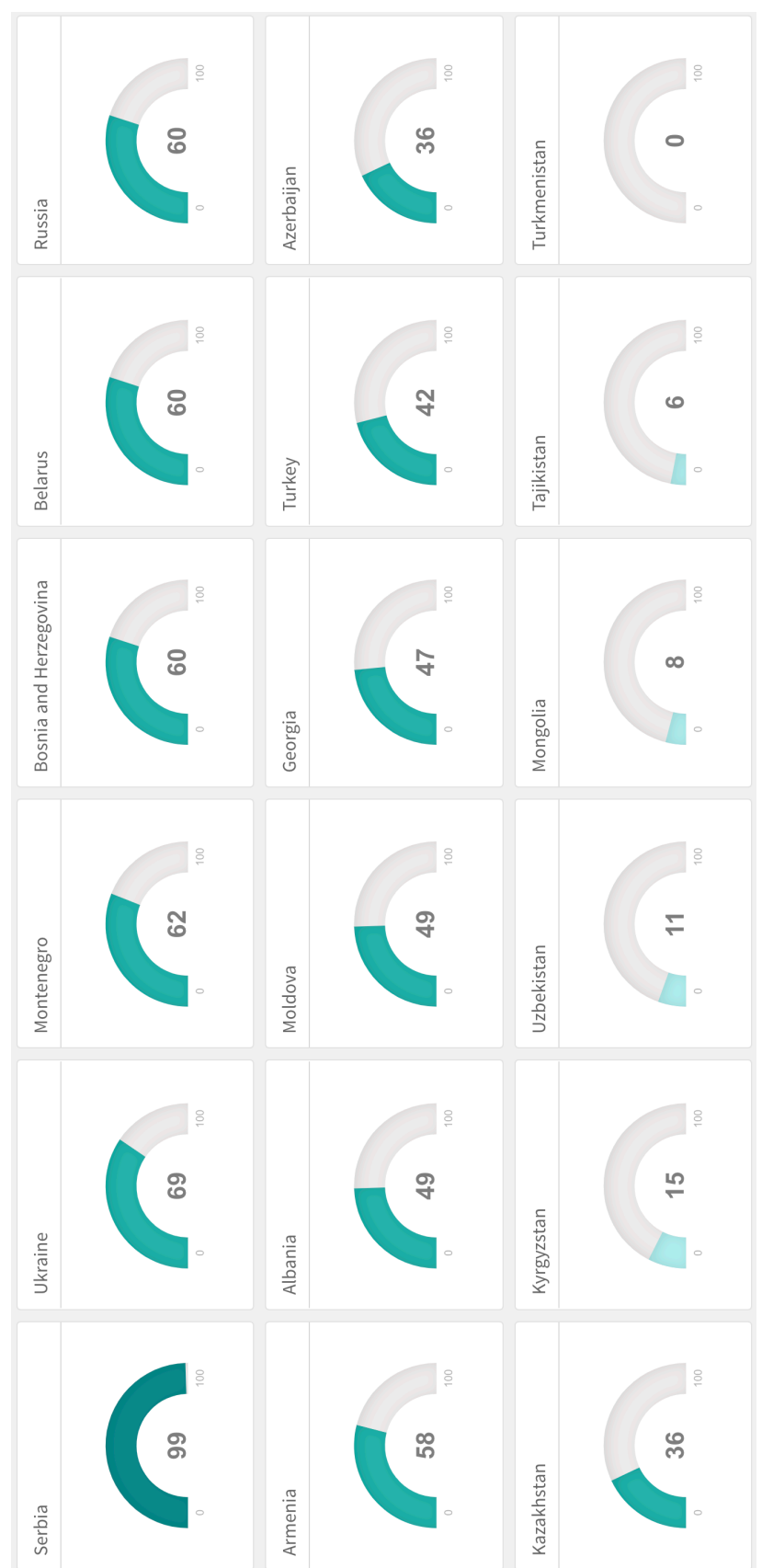

Fig. 1. Overall ranking of digital development of Eastern European and Central Asian countries according to four factors: e-services, online labor markets, online knowledge creation and access to online knowledge. 


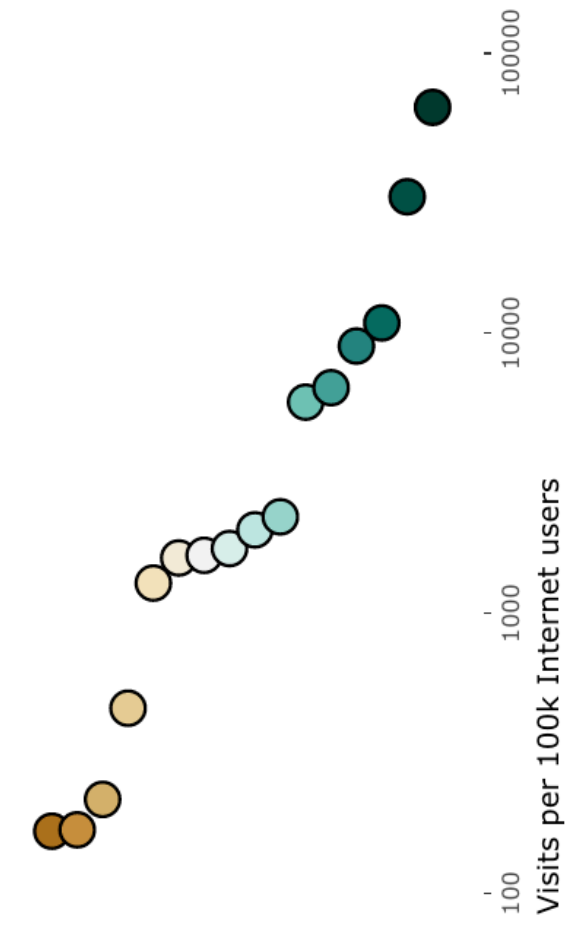

$\bigcirc$

○

- 우

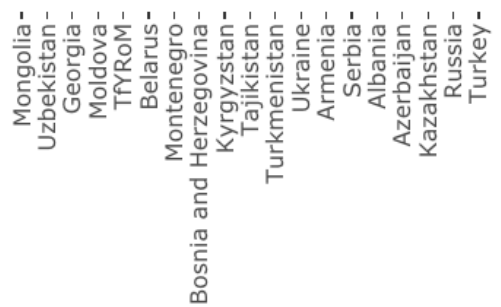

Fig. 2. The e-governance portals of Russia and Turkey are frequently visited sites. Similarly, the e-service portals of Kazakhstan, Azerbaijan, Serbia, and Albania are popular web-pages, too. 


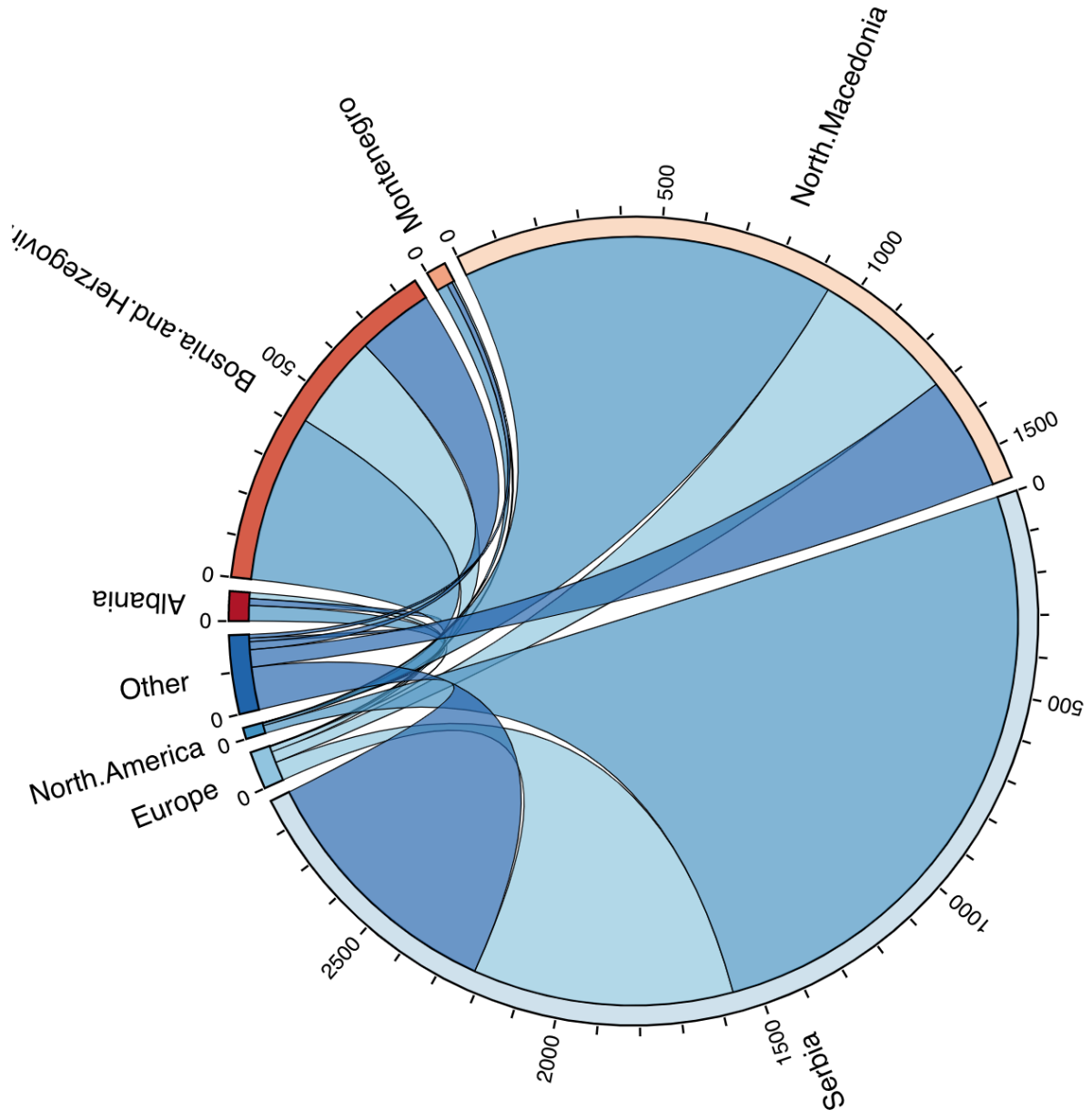

Fig. 3. Network flows of the Western Balkans online labour market. 


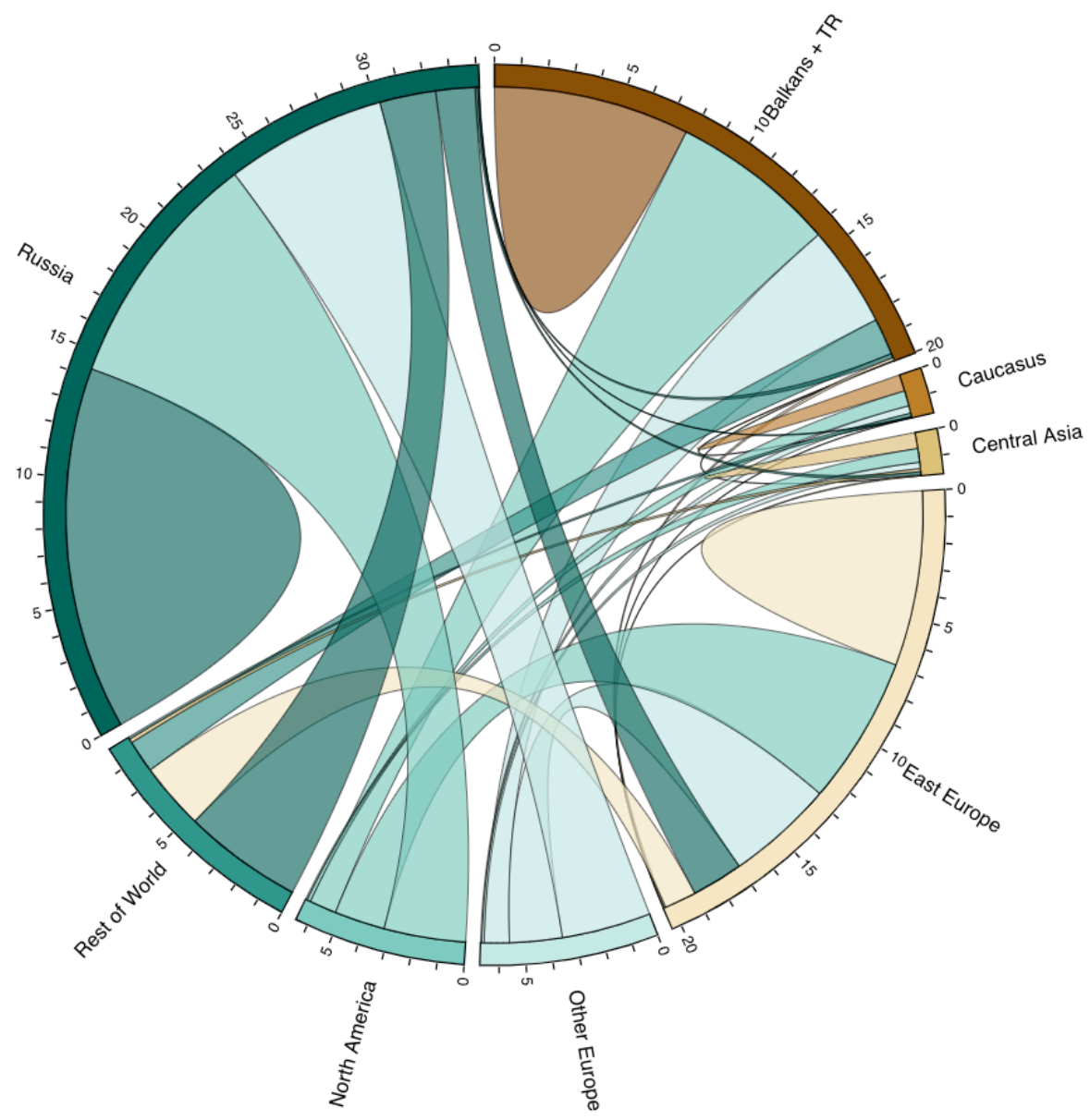

Fig. 4. On GitHub, $10 \%$ of all follow-relations that involve at least one user from the region, represent Russian users who follow programmers from North America. In contrast, only $3 \%$ of the network flows go into the other direction. 


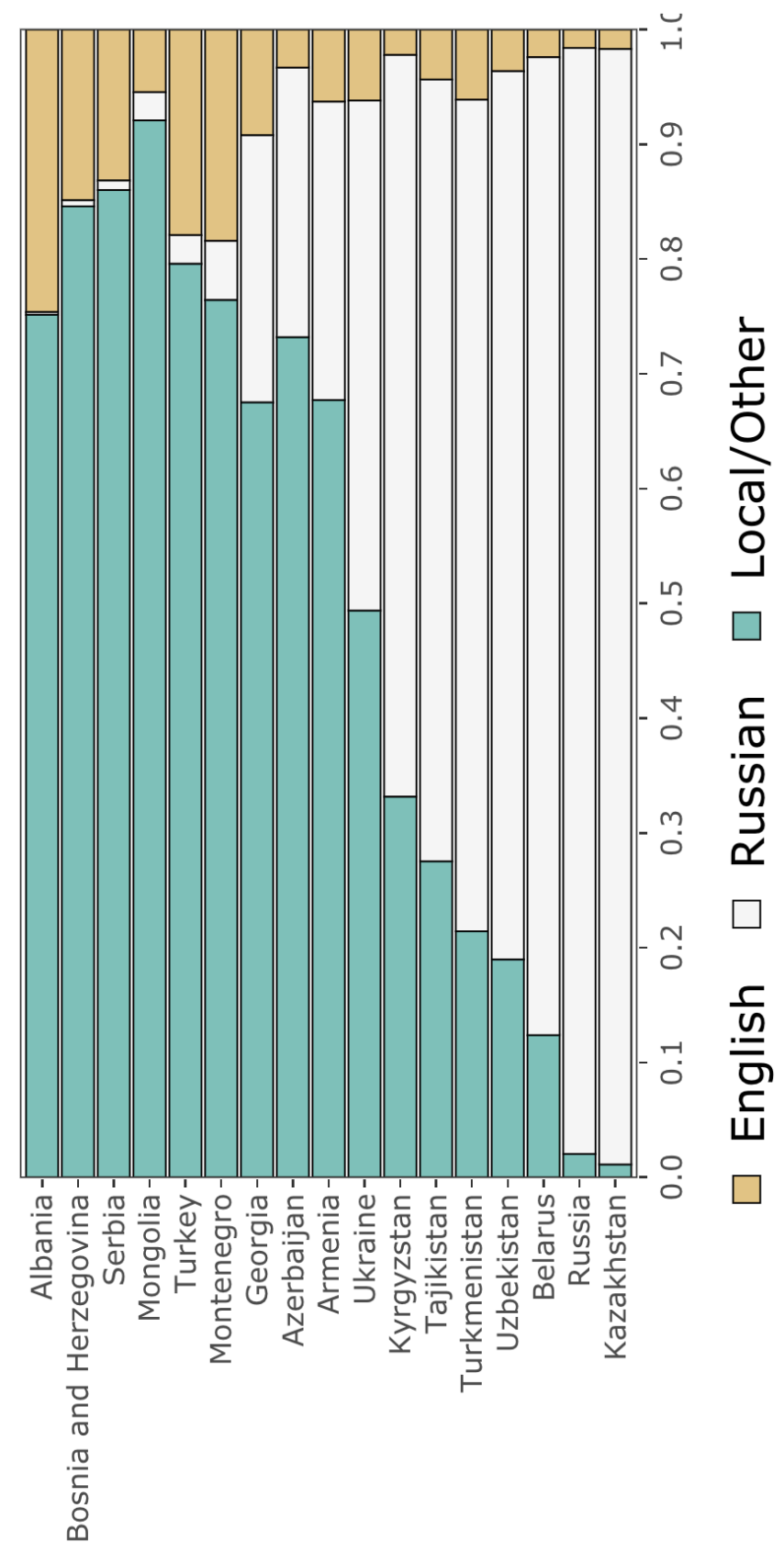

Fig. 5. Clicks to Wikipedia language editions from countries of the region. 


\section{References}

1. Stephany, F., Stoehr, N., Darius, P., Neuhäuser, L., Teutloff, O., and Braesemann, F. (2020c). The CoRisk-Index: A data-mining approach to identify industry-specific risk assessments related to COVID-19 in real-time. arXiv preprint arXiv:2003.12432.

2. Stephany, F. (2020) 'It's not only size that matters: determinants of Estonia's e-governance success', Electronic Government, Vol. 16, No. 3, pp.304-313.

3. Kässi, O., and Lehdonvirta, V. (2018). Online labour index: Measuring the online gig economy for policy and research. Technological forecasting and social change, 137, 241-248.

4. Stephany, F., Dunn, M., Sawyer, S., and Lehdonvirta, V. (2020). Distancing bonus or downscaling loss? The changing livelihood of US online workers in times of Covid-19.

5. Braesemann, F., Lehdonvirta, V., and Kässi, O. (2020). ICTs and the urban-rural divide: can online labour platforms bridge the gap?. Information, Communication and Society, 1-21.

6. Stephany, F., Braesemann, F., and Graham, M. (2020a). Coding together-coding alone: the role of trust in collaborative programming. Information, Communication and Society, 1-18.

7. Braesemann, F., Stoehr, N., and Graham, M. (2019). Global networks in collaborative programming. Regional Studies, Regional Science, 6(1), 371-373.

8. Stephany, Fabian, and Fabian Braesemann. "An exploration of wikipedia data as a measure of regional knowledge distribution.” In International Conference on Social Informatics, pp. 31-40. Springer, Cham, 2017. 